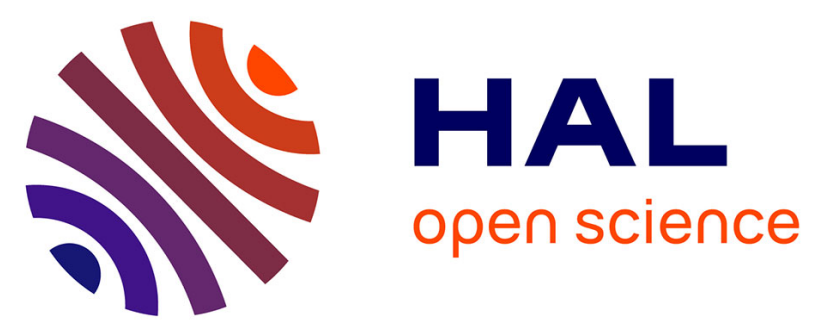

\title{
Isomer separation and effect of the degree of polymerization on the gas-phase structure of chondroitin sulfate oligosaccharides analyzed by ion mobility and tandem mass spectrometry
}

Salomé Poyer, Chrystel Lopin-Bon, Jean-Claude Jacquinet, Jean-Yves Salpin, Régis Daniel

\section{To cite this version:}

Salomé Poyer, Chrystel Lopin-Bon, Jean-Claude Jacquinet, Jean-Yves Salpin, Régis Daniel. Isomer separation and effect of the degree of polymerization on the gas-phase structure of chondroitin sulfate oligosaccharides analyzed by ion mobility and tandem mass spectrometry. Rapid Communications in Mass Spectrometry, 2017, 31 (23), pp.2003 -2010. 10.1002/rcm.7987 . hal-01637356

\author{
HAL Id: hal-01637356 \\ https://hal.science/hal-01637356
}

Submitted on 3 Oct 2018

HAL is a multi-disciplinary open access archive for the deposit and dissemination of scientific research documents, whether they are published or not. The documents may come from teaching and research institutions in France or abroad, or from public or private research centers.
L'archive ouverte pluridisciplinaire HAL, est destinée au dépôt et à la diffusion de documents scientifiques de niveau recherche, publiés ou non, émanant des établissements d'enseignement et de recherche français ou étrangers, des laboratoires publics ou privés. 


\section{Isomer separation and effect of the polymerization degree on the gas-phase structure of chondroitin sulfate oligosaccharides analyzed by ion mobility-tandem mass spectrometry}

Salomé Poyer, ${ }^{1}$ Chrystel Lopin-Bon, ${ }^{2}$ Jean-Claude Jacquinet, ${ }^{2}$ Jean-Yves Salpin, ${ }^{1}$ Régis Daniel. $^{1}{ }^{*}$

1. Université Paris-Saclay, CNRS, CEA, Univ Evry, Laboratoire Analyse et Modélisation pour la Biologie et l'Environnement, F-91025, Evry, France

2. ICOA, CNRS UMR 7311, Université d'Orléans, F-45067 Orléans

*Correspondence to: R. Daniel, Laboratoire Analyse et Modélisation pour la Biologie et l'Environnement, CNRS, UMR 8587, Université Evry-Val-d'Essonne, 91025 Evry Cedex, France.

E-mail: regis.daniel@univ-evry.fr

RATIONALE: Chondroitin sulfate (CS) glycosaminoglycans are bioactive sulfated polysaccharides comprising repeating units of uronic acid and $\mathrm{N}$-acetyl galactose sulfated at various positions. The optimal length and sulfation pattern of the CS bioactive sequences remain elusive so that structure-activity relationship cannot be easily established. Development of efficient analytical methods allowing the differentiation of the various sulfation patterns of CS sequences is therefore of particular importance to correlate their biological functions to the sulfation pattern.

METHODS: Discrimination of different oligomers (dp2 to dp6) of synthetic chondroitin sulfate isomers was evaluated by electrospray ionization/tandem mass spectrometry (ESI-MS/MS) in the negative-ion mode from deprotonated and alkali adducts species. In addition, ion mobilitymass spectrometry (IMS-MS) was used to study the influence of both the polymerization degree and sulfate group location onto the gas-phase conformation of CS oligomers.

RESULTS: ESI-MS/MS spectra of chondroitin sulfate isomers show characteristic product ions exclusively from alkali adduct species ( $\mathrm{Li}, \mathrm{Na}, \mathrm{K}$ and $\mathrm{Cs}$ ). Whatever the alkali adducts studied, MS/MS of chondroitin oligosaccharides sulfated at position 6 yields a specific product ion at $\mathrm{m} / \mathrm{z}$ 139 while CS oligosaccharides sulfated at position 4 show a specific product ion at $\mathrm{m} / \mathrm{z} 154$. Being observed for the different CS oligomers di-, tetra- and hexa-saccharides, these fragment 
ions are considered as diagnostic ions for chondroitin 6- $O$-sulfate and chondroitin 4- $O$-sulfate, respectively. IMS-MS experiments reveal that collision cross sections (CCS) of CS oligomers with low charge states evolved linearly with polymerization degrees indicating a similar gasphase conformation.

CONCLUSIONS: This study allows the fast and unambiguous differentiation of CS isomers sulfated at position 6 or 4 for both saturated and unsaturated analogues from tandem mass spectrometry experiments. In addition, the CCS linear evolution of CS oligomers in function of the polymerization degree indicates that no folding occurs even for hexa-saccharides.

\section{Keywords}

Chondroitin sulfate, glycosaminoglycans, isomers, ion mobility spectrometry, tandem mass spectrometry 
Chondroitin sulfate (CS) glycosaminoglycans (GAGs) are bioactive sulfated polysaccharides comprising 40-200 repeating units of D-glucuronic acid (D-GlcA) and 2-acetamido-2-deoxy-Dgalactose (D-GalNAc) sulfated at various positions. D-GalNAc may contain a 6-O-sulfate group (CS-C) or/and a 4- $O$-sulfate group (CS-A/CS-E), and D-GlcA may be sulfated at the 2-O or 3-O position, thus leading to a huge diversity of the CS sequence (Scheme 1). ${ }^{[1,2]}$ Besides its wellknown structural function in the extra-cellular matrix, major biological roles have been recently highlighted in cellular communication and development. ${ }^{[3-8]}$ Being present in the brain, articulations, placenta, and immune system, CS play critical roles in various physio-pathological processes. ${ }^{[8-10]} \mathrm{CS}$ is the most abundant GAG in the central nervous system where it is involved in neural development and regeneration, cell migration and axonal pathfinding. ${ }^{[1-13]}$ These functions are mediated through interaction of specific CS sequences with cytokines, growth factors and guidance molecules. ${ }^{[14-16]}$ To date however, the optimal length and sulfation pattern of these bioactive sequences remain elusive so that structure-activity relationship could not be easily established. In this context, development of efficient analytical methods for the sensitive detection and discrimination of the various sulfation patterns of CS sequences is of high necessity to associate these biological functions with well-defined sulfated CS structures.
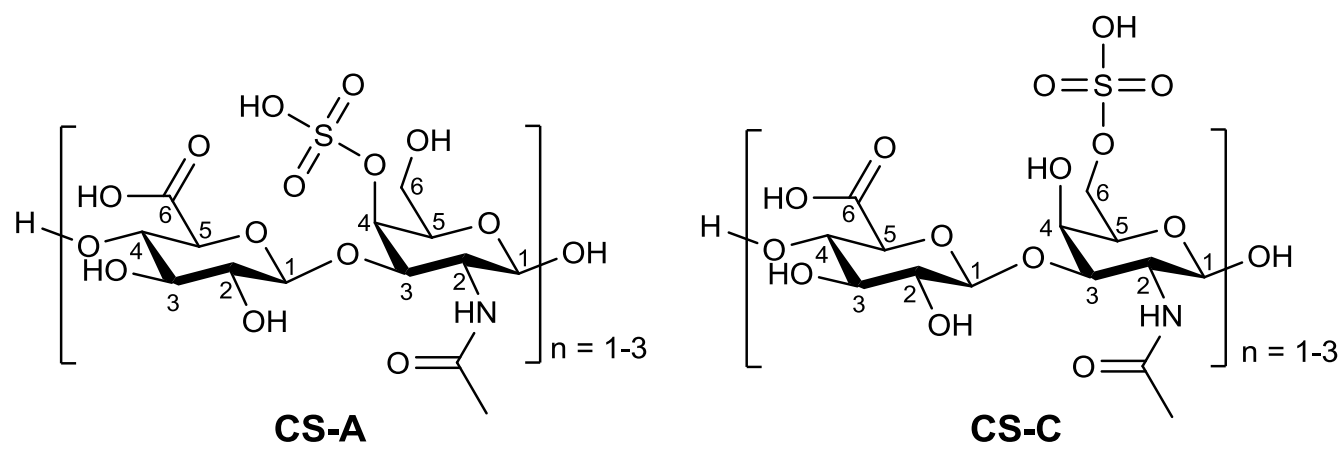

Scheme 1. Chemical structure of the studied synthetic chondroitin sulfate oligosaccharides.

Mass spectrometry (MS) using the soft ionization technique electrospray (ESI) has been widely recognized as a powerful and highly sensitive method for the structural analysis of sulfated GAGs. ${ }^{[17,18]}$ The fine structural analysis of GAGs by MS is most commonly carried out on GAGs fragments, mainly at the disaccharide (dp2) level, after the enzymatic or chemical depolymerization of the GAGs chain. Different studies have reported the comprehensive MS characterization of the various sulfated dp2 isomers from glucosaminoglycans allowing decisive progresses in the compositional analysis and profiling of heparin and heparan sulfate from multiple origins. ${ }^{[19-24]}$ Less data are comparatively available for galactosaminoglycan-derived oligosaccharides, especially as regards the detailed characterization of chondroitin sulfate 
oligosaccharides. ${ }^{[25-30]}$ Previous studies showed that MS/MS fragmentation of CS-A and CS-C dp2 produced identical $Y_{1}$ and $Z_{1}$ fragments with different respective intensities. ${ }^{[31,32]}$ Therefore, the determination of the $4 \mathrm{~S} / 6 \mathrm{~S}$ sequence of CS could not rely unambiguously on these fragment ions only, but must also involve the measurement of their intensity or further multistage $\left(\mathrm{MS}^{\mathrm{n}}\right)$ collision-induced dissociation. ${ }^{[33]}$ In the present study, we have investigated the MS characterization of synthetic CS oligosaccharides of well-defined structure, while most of the previous studies were performed with oligosaccharides prepared by partial enzymatic depolymerization of CS from animal sources. Tandem mass spectrometry (MS/MS) and ion mobility-mass spectrometry (IMS-MS) were carried out for the first time on synthetic CS oligosaccharides sulfated in position 4 (CS-A), and 6 (CS-C) of the D-GalNAc unit. IMS, which allows the separation of ionic molecules according to their size and shape in gas phase, has recently emerged as a powerful method to resolve isomeric and isobaric GAGs structures and to provide further insight into the three dimensional structures of GAGs ions. ${ }^{[34]}$ Mainly applied to hyaluronan, heparin and heparan sulfate oligosaccharides, ${ }^{[35-38]}$ IMS-MS has been rarely used for the characterization of CS oligosaccharides to date. ${ }^{[39]}$ The present work demonstrates that tandem MS provides unambiguous MS/MS diagnostic ions allowing the differentiation of isomeric di-, tetra- and hexa-saccharides of CS-A and CS-C, and that the IMS-MS study brings new insights into the effects of the cationization, polymerization degree and number of sulfate moiety, onto the gas-phase structure. 


\section{EXPERIMENTAL}

\section{Chemicals and standards}

Synthetic sugars of pure di-, tetra- and hexa-CS-A and CS-C were kindly prepared as previously described. ${ }^{[40]}$ Natural CS-C and CS-A disaccharides were purchased from Iduron (Cheshire, UK) and Dextra Laboratories (Reading, UK), respectively. HPLC-grade methanol was supplied by VWR, Dextran standard 1000 and 5000 from Leuconostoc mesenteroides, lithium, sodium and potassium acetate, formic acid, $\mathrm{NaH}_{2} \mathrm{PO}_{4}$, and $\mathrm{CsOH}$ from Sigma-Aldrich (Saint Louis MO, USA). Deionised water (18.2 M $\Omega$ ) was obtained from a Milli-Q (Millipore) purification system.

\section{ESI-IMS-TOF-MS/MS analysis}

Ion mobility-mass spectrometry (IMS-MS) experiments were carried out using the travelling wave ion mobility cell of the Synapt G2-Si HDMS instrument. Details of the instrument have been published elsewhere. ${ }^{[41]}$ Experiments were performed using the ' $\mathrm{V}$ ' resolution mode in the 50 to 2000 mass range. The ESI source was operated in the negative ionization mode using the following voltage parameters: parameters capillary $2.3 \mathrm{kV}$, sampling cone $0 \mathrm{~V}$, source offset 50 $\mathrm{V}$. The source temperature was set to $70^{\circ} \mathrm{C}$ and the desolvation gas temperature to $200^{\circ} \mathrm{C}$ with a flow gas of $200 \mathrm{~L} \mathrm{hr}^{-1}$. MS/MS experiments were carried out in the trap cell of the instrument.

Optimized IMS conditions were with the following parameters: wave velocity $800 \mathrm{~m} \mathrm{~s}^{-1}$, wave height of $40 \mathrm{~V}, \mathrm{~N}_{2}$ IMS gas flow $90 \mathrm{~mL} \mathrm{~min}^{-1}$, and Helium cell gas flow $180 \mathrm{~mL} \mathrm{~min}{ }^{-1}$. In addition, different IMS parameters were used depending on the polymerization degree and charge state to obtain accurate CCS values.

Experimental CCS values were estimated with the calibration method described in the literature using dextran as references to correct the non-uniform electric field of the TWIM cell. ${ }^{[42]}$ Solution of dextran $\mathrm{M}_{\mathrm{w}} 1000$ and 5000 was prepared as mentioned by Hofmann et al. and used to calibrate CCS values from simply charged ions. ${ }^{[43]}$

\section{ESI-QIT-MS ${ }^{\mathbf{n}}$ analysis}

$\mathrm{MS}^{\mathrm{n}}$ experiments were performed using a quadrupole ion trap mass spectrometer (AmaZon Speed ETD, Bruker) equipped with an Apollo electrospray source operated in the negative ionization mode. $\mathrm{MS}^{\mathrm{n}}$ experiments were carried out in enhanced resolution mode in the 50 to 600 mass range. ESI source parameters were set as follows: capillary voltage $3.5 \mathrm{kV}$, end plate offset $-300 \mathrm{~V}$, nebulizer gas flow $20 \mathrm{psi}$, dry gas flow $10 \mathrm{~L} \mathrm{~min}^{-1}$ and dry gas temperature $250{ }^{\circ} \mathrm{C}$. Data analysis v4.0 software was used to process data. 


\section{DFT calculation}

Molecular orbital calculations were carried out using the B3LYP density functional ${ }^{[44,45]}$ as implemented in the Gaussian-09 set of programs. ${ }^{[46]}$ The different complexes considered were optimized using the $6-31+\mathrm{G}(\mathrm{d}, \mathrm{p})$ basis set, without any symmetry constraint, by assuming that each sugar unit retained its ${ }^{4} \mathrm{C}_{1}$ ring conformation. To describe the metallic center, we used for $\mathrm{Li}$, $\mathrm{Na}$ and $\mathrm{K}$ the standard Pople basis sets. For Cs, we used the LANL2DZ effective core potential and basis set of Hay and Wadt, ${ }^{[47-49]}$ the basis set being augmented by the Glendening polarization function. ${ }^{[50]}$ Harmonic vibrational frequencies were calculated at this level to characterize the stationary points as local minima or saddle points, and to obtain the zero-point vibrational energy (ZPE) corrections. Trajectory method algorithm of the MOBCAL software modified by Campuzano et al. ${ }^{[51]}$ was used to convert Cartesian coordinates in CCS values. Lennard-Jones parameters of alkali atoms were based on the scaled Universal Force Field. ${ }^{[52,53]}$

\section{RESULTS AND DISCUSSION}

\section{Isomeric distinction by $E S I-M S / M S$}

Differentiation of synthetic CS-A (4- $O$-sulfated) and CS-C (6-O-sulfated) isomers was investigated by tandem mass spectrometry using different oligomers (di-, tetra- and hexasaccharides). In order to improve MS/MS isomeric differentiation, alkali adducts were studied for each isomer. Figure 1 shows MS/MS spectra obtained with synthetic CS-A and CS-C disaccharides for $[\mathrm{M}-\mathrm{H}]^{-},[\mathrm{M}-2 \mathrm{H}+\mathrm{Li}]^{-},[\mathrm{M}-2 \mathrm{H}+\mathrm{Na}]^{-},[\mathrm{M}-2 \mathrm{H}+\mathrm{K}]^{-}$, and $[\mathrm{M}-2 \mathrm{H}+\mathrm{Cs}]^{-}$ions. Interaction with alkali metal ions promotes additional deprotonation of the sugars. Similar behavior has been already observed for heparin disaccharides when interacting with metal ions. ${ }^{[54]}$ While no isomer-specific fragment ions were observed from MS/MS analysis of deprotonated species, isomer distinction could easily be achieved for alkali cation adducts. 


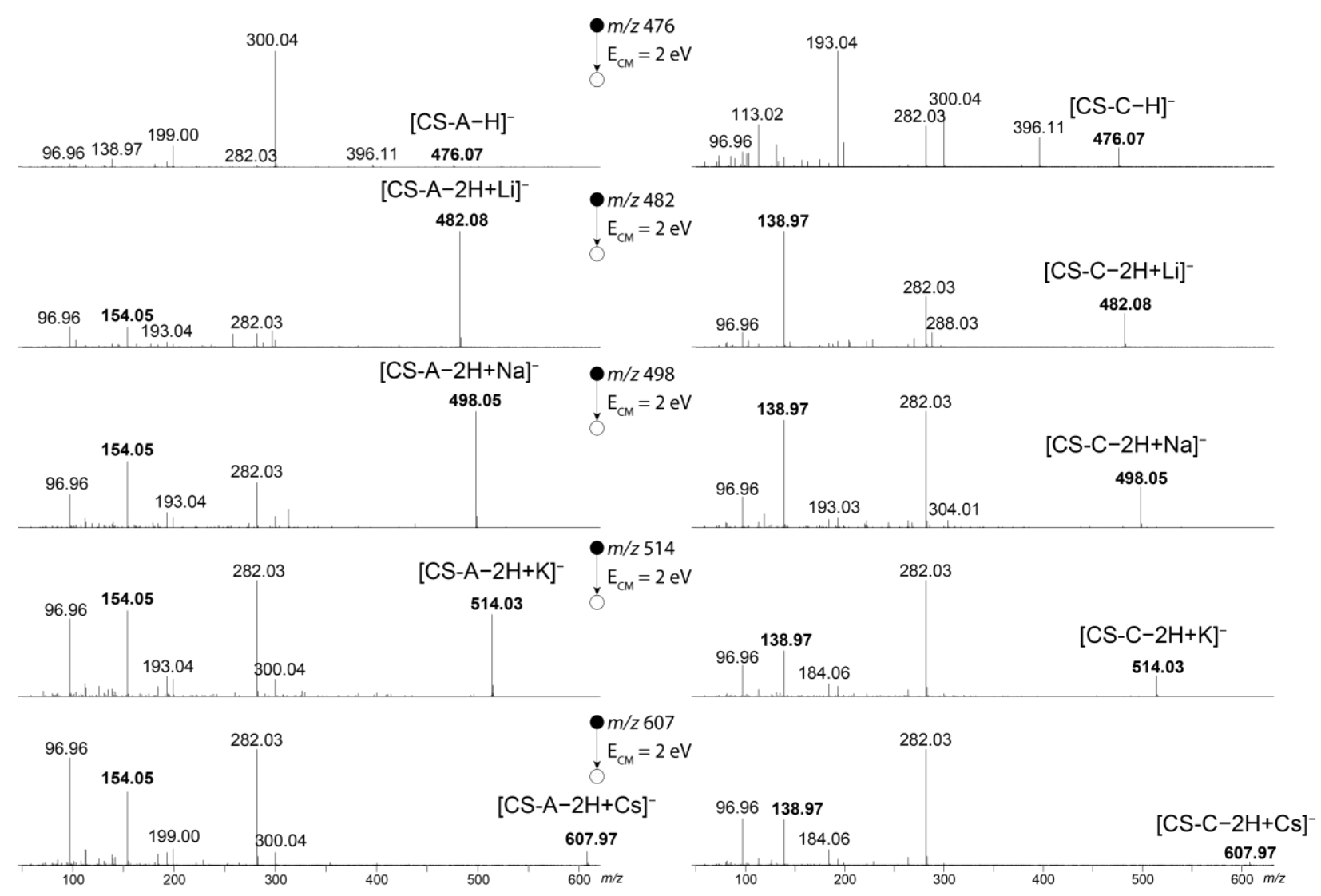

Figure 1. CID product ion spectra of synthetic disaccharide CS-A (on the left) and CS-C (on the right) from deprotonated and alkali adduct species. MS/MS spectra of tetra and hexa-saccharides compounds are reported in the Figure S1 and Figure S2, Supporting Information.

MS/MS spectra of the $[\mathrm{M}-\mathrm{H}]^{-}$ions share common fragmentations. The general sugar fragmentation convention introduced by Domon and Costello was used to assign the various fragment ions. ${ }^{[55]}$ The $m / z 396$ ion results from the loss of $\mathrm{SO}_{3}$. Ions arising from the glycosidic bond cleavages are detected at $m / z 300\left(\mathrm{Y}_{1}\right), m / z 282\left(\mathrm{Z}_{1}\right)$ and $m / z 193\left(\mathrm{C}_{1}\right)$, the $\mathrm{B}_{1}$ ion $(m / z$ 175) being not observed. The $\mathrm{Y}_{1} / \mathrm{Z}_{1}$ abundance ratio differs markedly for these isomers, as already observed previously. ${ }^{[31,32]}$ The abundance of the $\mathrm{C}_{1}$ ion also varies significantly. Other abundant ions are detected like $m / z, 97\left(\mathrm{HSO}_{4}{ }^{-}\right)$but also cross-ring fragments, such as $m / z, 199\left({ }^{1,3} \mathrm{X}_{0}\right)$. The $\mathrm{m} / \mathrm{z} 139$ ion can be assigned to ${ }^{0,4} \mathrm{~A}_{2}$ for CS-C isomer, but is also observed on the MS/MS spectrum of deprotonated CS-A. Therefore, these results show that for $[\mathrm{M}-\mathrm{H}]^{-}$species, different intensities of the main fragment ions were detected depending on the isomer studied, but no diagnostic fragment ion could be identified.

Examination of Figure 1 shows that interaction of the metal ion strongly favors the formation of the $\mathrm{Z}_{1}$ ion with respect to the $\mathrm{Y}_{1}$ ions. But the most striking result is that the different alkali adduct species studied showed two diagnostic fragment ions allowing isomeric differentiation: $m / z 154\left(\mathrm{C}_{7} \mathrm{O}_{3} \mathrm{H}_{8} \mathrm{~N}^{-}\right)$for CS-A and $m / z 139\left(\mathrm{C}_{2} \mathrm{O}_{5} \mathrm{H}_{3} \mathrm{~S}^{-}\right)$for CS-C ions. A structure is proposed 
for these two fragment ions in Figure 2a. While the fragment ion at $m / z \quad 139$ for CS-C, corresponding to ${ }^{0,4} A_{2}$, is directly obtained, the fragment ion at $\mathrm{m} / \mathrm{z} 154$ requires a rearrangement involving the sulfate group stabilization by the presence of the metal cation. To determine the structure of the diagnostic fragment ion of CS-A and understand the unusual behavior of sugar fragmentation, $\mathrm{MS}^{\mathrm{n}}$ experiments were performed. $\mathrm{MS}^{\mathrm{n}}$ experiments carried out at low collision energy indicated four consecutive losses from $[\mathrm{CS}-\mathrm{A}-2 \mathrm{H}+\mathrm{Na}]^{-}$to generate the ion at $\mathrm{m} / \mathrm{z}, 154$ (Figure 2b). A mechanism is proposed (Figure 2c) from the opened form of $\left[Z_{l}+\mathrm{Na}\right]^{-}$ion $(\mathrm{m} / z$ 304), involving a charge-driven loss of $\mathrm{CH}_{2} \mathrm{O}$, followed by both charge and proton transfers prior to elimination of the $\mathrm{NaHSO}_{4}$ group.

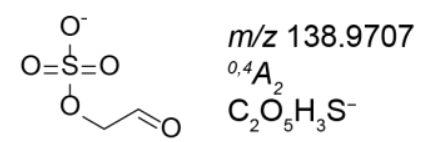

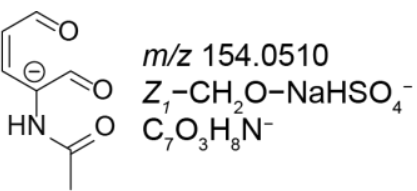

(b)

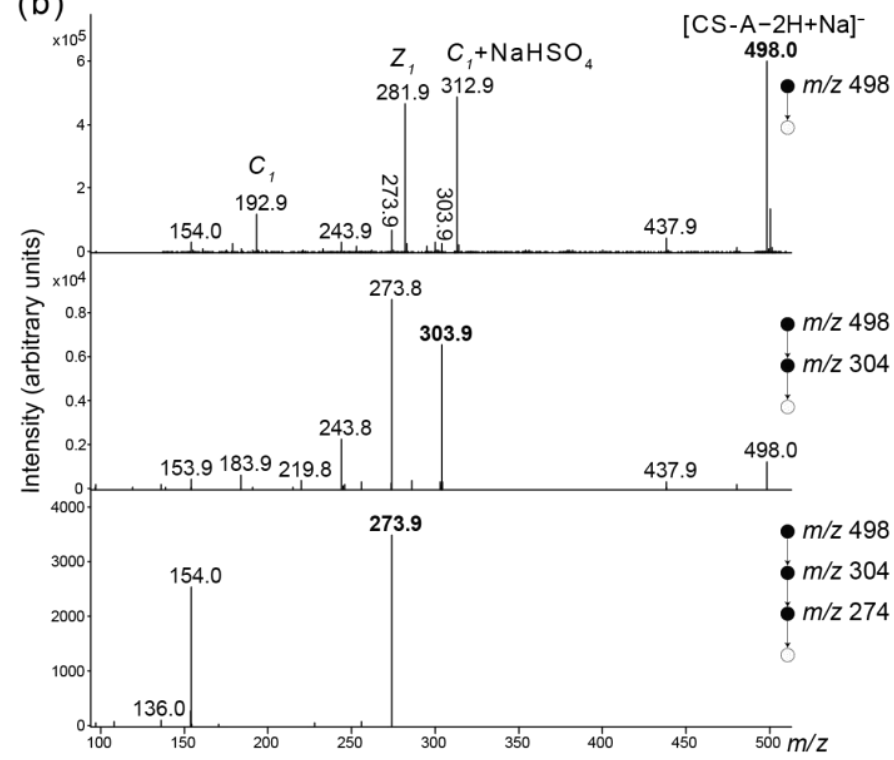

(c)

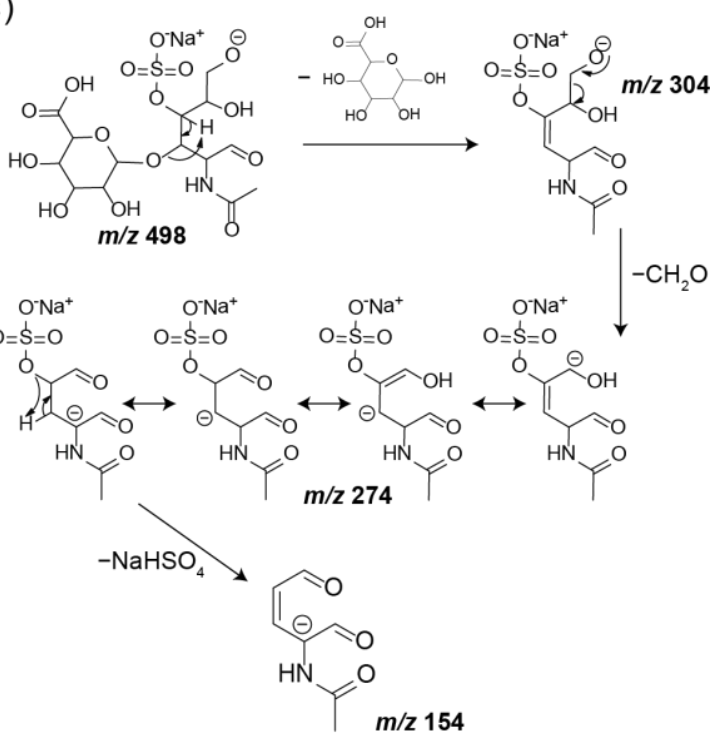

Figure 2. (a) structures proposed for diagnostic fragment ions of CS-A and CS-C from alkali adduct species. (b) $\mathrm{MS}^{\mathrm{n}}$ spectra from synthetic disaccharide [CS-A-2H+Na] ${ }^{-}$used to propose the fragmentation mechanism (c) accounting for $m / z$ 154. See Table S1 and S2 for exact mass measurement.

These specific fragment ions were also observed from tetra- and hexa-saccharides (Figure S1 and Figure S2, Supporting Information). Note that for tetra-saccharides, $[\mathrm{CS}-3 \mathrm{H}+\mathrm{Alk}]^{2-}$ did not allowed isomeric separation, while $[\mathrm{CS}-4 \mathrm{H}+2 \mathrm{Alk}]^{2-}$ showed the above-mentioned specific fragment ions for CS-A and CS-C. For hexa-saccharides, $[\mathrm{CS}-6 \mathrm{H}+3 \mathrm{Alk}]^{3-}$ species were required to observe specific fragment ions as the $\mathrm{m} / \mathrm{z} .154$ was not observed from $[\mathrm{CS}-5 \mathrm{H}+2 \mathrm{Alk}]^{3-}$ and $[\mathrm{CS}-4 \mathrm{H}+\mathrm{Alk}]^{3-}$. These results indicate that a minimum of one metal cation per sulfate moiety 
was required to form the diagnostic fragment ions of CS isomers, which is in accordance with the proposed fragmentation pathway of the ion at $\mathrm{m} / \mathrm{z} 154$.

It is worth noting that the diagnostic fragment ions at $m / z 154$ and $m / z, 139$ are also observed with natural chondroitin sulfate isomers, which differ from the synthetic species by a double bond between $\mathrm{C}_{4}$ and $\mathrm{C}_{5}$. This unsaturation results from the enzyme (lyase)-catalyzed glycosidic bond cleavage. Based on the analyses carried out on natural disaccharide isomers (Figure S3, Supporting Information), we assume that fragment ions at $\mathrm{m} / \mathrm{z} 154$ and $\mathrm{m} / \mathrm{z} 139$ are also diagnostic for natural chondroitin sulfate isomers.

\section{Gas-phase conformation}

Influence of the cation

In addition to allowing isomeric discrimination, the use of alkali cations increases the gas-phase stability of CS analogues, independently of the isomers and of the polymerization degree studied. Relative stabilities of the different alkali adducts formed with CS analogues were determined from MS/MS experiments (Figure S4). Difference in stability was observed for CS-A and CS-C depending on the cation. CS stability increased strongly from $[\mathrm{M}-\mathrm{H}]^{-}$to $[\mathrm{M}-2 \mathrm{H}+\mathrm{Li}]^{-}$for $\mathrm{CS}-\mathrm{A}$ and then decrease when the cation size increased. By contrast, the relative stability of CS-C adducts calculated from MS/MS spectra at the same $E_{C M}$ did not show such stability improvement. Similar stability behaviors were observed for tetra- and hexa-CS-A from [tetraCS$\mathrm{A}-4 \mathrm{H}+2 \mathrm{Alk}]^{2-}$ and $[\text { hexa-CS-A-6H+3Alk }]^{3-}$ species only. 


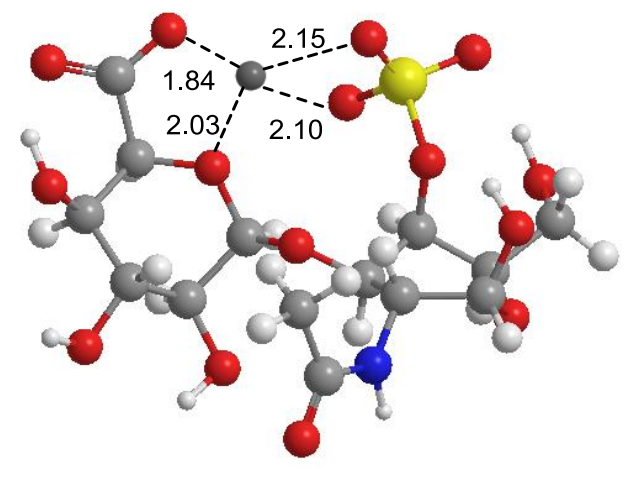

$\left[\mathrm{CS}-\mathrm{A}-2 \mathrm{H}+\mathrm{Li}^{-}\right.$

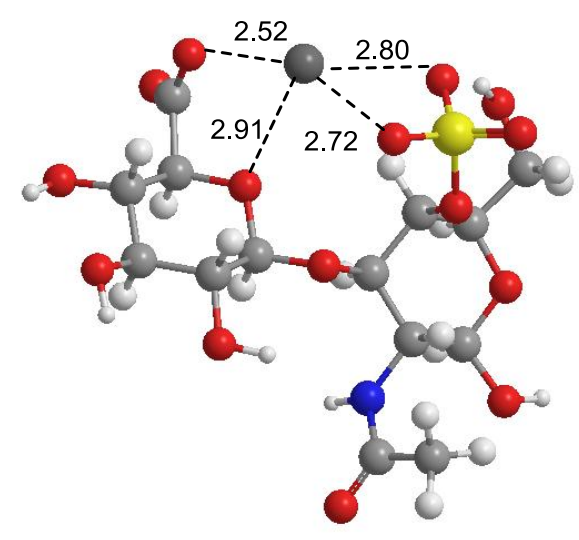

$[\mathrm{CS}-\mathrm{A}-2 \mathrm{H}+\mathrm{K}]^{-}$

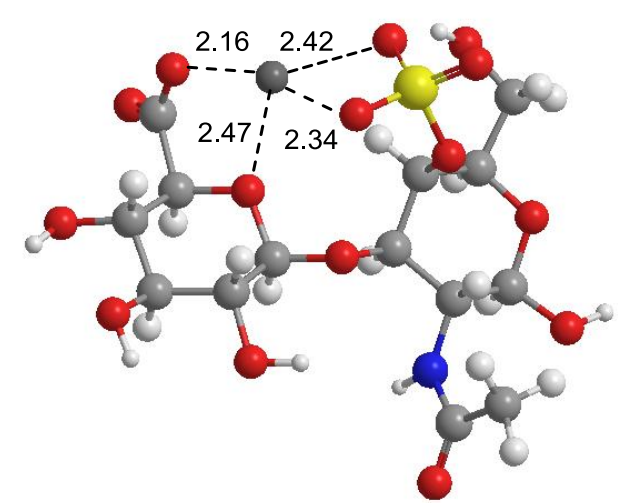

$[\mathrm{CS}-\mathrm{A}-2 \mathrm{H}+\mathrm{Na}]^{-}$

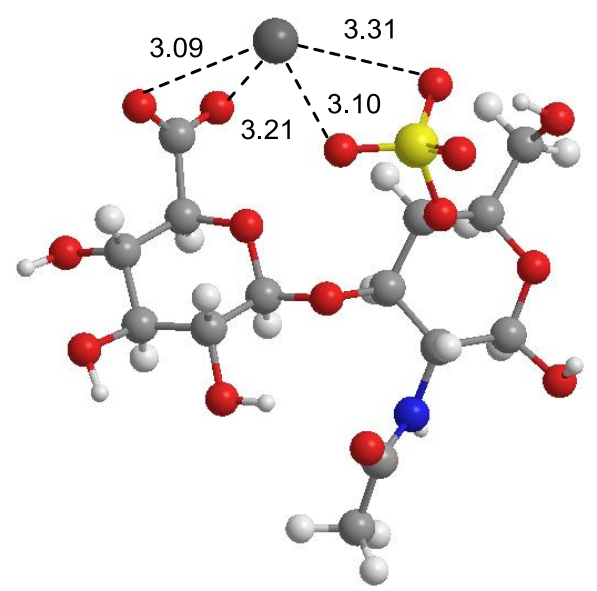

$[\mathrm{CS}-\mathrm{A}-2 \mathrm{H}+\mathrm{Cs}]^{-}$

Figure 3. Preferred binding scheme for $[\mathrm{CS}-\mathrm{A}-2 \mathrm{H}+\mathrm{Alk}]^{-}$complexes according to DFT calculations. Interaction distances are given in Ångstroms.

DFT calculations have been carried out in order to get some insights into the preferred binding scheme between the metals and the CS disaccharides. The most favorable binding scheme obtained for each alkali metal and CS-A disaccharides is given in Figure 3. For both CS-A and CS-C disaccharides, the most stable forms correspond to structures in which the metal interacts with both the carboxylate and the sulfate groups. Depending on the alkali metal cation, slightly different chelation schemes are observed. For lithium, sodium and potassium adducts, the chelation within the alkali adducts involves three groups, i.e. sulfate group, the carboxylate group and the intra-cyclic oxygen of the glucuronic acid for CS-A isomers. By contrast, chelation with cesium involves only the sulfate and the carboxylate groups due to steric hindrance with the metal adduct. These chelations lead to a folding of the CS-A structures around the cation, and to an increase of the interaction distances with the cation size. The metal chelation involving three groups particularly stabilize the structure of CS-A adducts. On the 
other hand, the different position of the sulfate group on CS-C isomers results in less pronounced folding of the sugar backbone required to chelate the cation between carboxylate and sulfate groups (see Figure S5). Other binding schemes have also been explored for the CS-A disaccharide. For the complexes with lithium and sodium, bidentate interactions involving either the carboxylate or the sulfate group could be located on the potential energy surface (Figure S6). Although being minima on the potential energy surfaces, these structures are sensibly less stable as they are located more than $150 \mathrm{~kJ} / \mathrm{mol}$ above the global minima. These data clearly demonstrate that simultaneous interaction with both groups is clearly favored, as previously observed in metal/Hp disaccharide complexes. ${ }^{[54]}$ For potassium and cesium, bidentate interaction with the sulfate group could also be located, whereas structures only involving interaction with the carboxylate group could not be optimized and systematically evolved toward tetradentate structures.

The combined interaction with the two negative groups is notably supported by the intense detection of $\left[C_{1}+\mathrm{NaHSO}_{4}\right]^{-}$ion from $[\mathrm{CS}-\mathrm{A}-2 \mathrm{H}+\mathrm{Na}]^{-}(\mathrm{m} / z, 313$, Figure $2 \mathrm{~b})$. As a matter of fact, the formation of $\left[C_{1}+\mathrm{NaHSO}_{4}\right]^{-}$ion requires the simultaneous breaking of the glycoside bond and the detachment of $\mathrm{HSO}_{4}{ }^{-}$from the D-GalNAc moiety. The ionic linkage of the cation to both sulfate and carboxylate groups may explain the migration of the sulfate group from the DGalNAc to the D-GlcA unit.

MS/MS experiments have been completed by ion mobility mass spectrometry (IMS-MS) experiments. IMS-MS has become an important tool to study the gas-phase conformation of biological compounds. Indeed, the use of ion mobility allows the determination of collision cross section (CCS) values, which are representative of the tridimensional structure of CS oligomers in the gas phase. Correlations between calculated and experimental CCS values can be plotted to get deeper insight into the folded structures of CS isomers induced by the metal cations. In addition, IMS-MS can be also used to differentiate isomers in the gas phase. In the particular case of the deprotonated form of CS disaccharide isomers, similar isomer CCS values were obtained so that isomeric differentiation could not be achieved (Figure 4). As regard the alkali metal adducts, synthetic disaccharide isomers CS-C and CS-A showed also similar behaviors depending on the cationic species analyzed by IMS-MS (Figure 4). For both isomers, the drift time increased with the cation size, and the order of magnitude of experimental CCS values is in agreement with theoretical structures involving interaction of carboxylate and sulfate moieties around the cation. These results thus confirmed the folding of the structure in such way that both sulfate and carboxylate moieties interact closely with the metal center. 
(a)
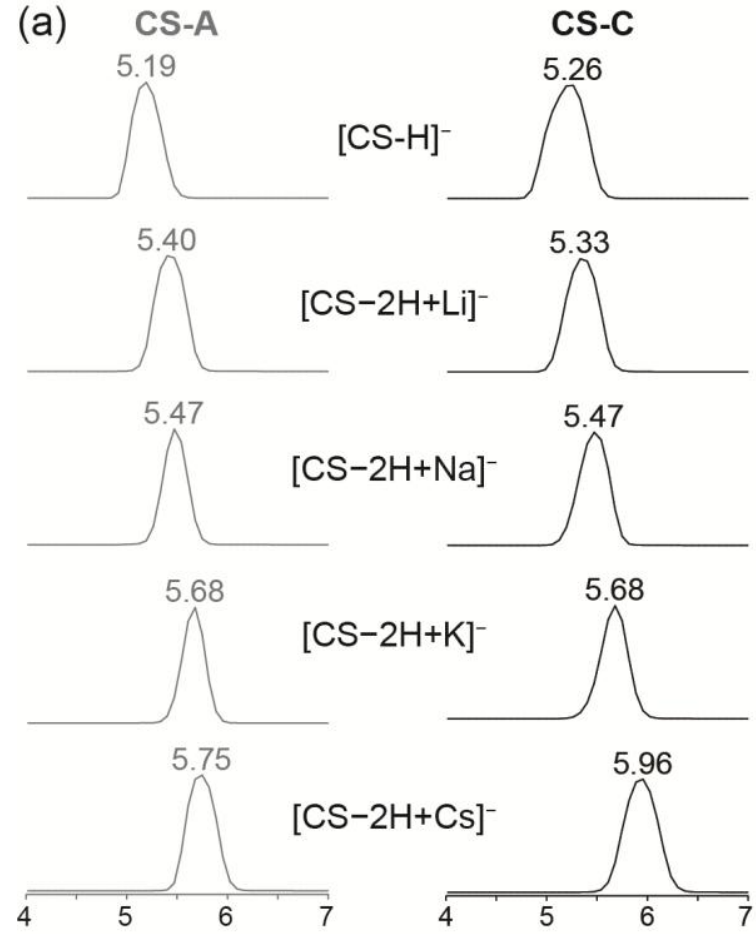

(b)

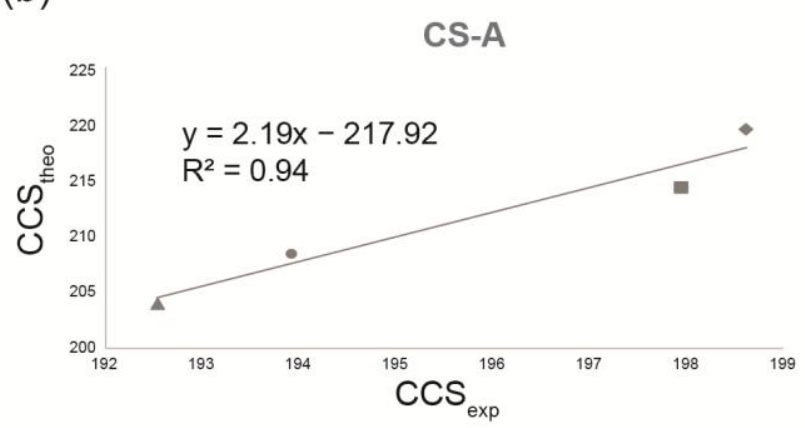

CS-C

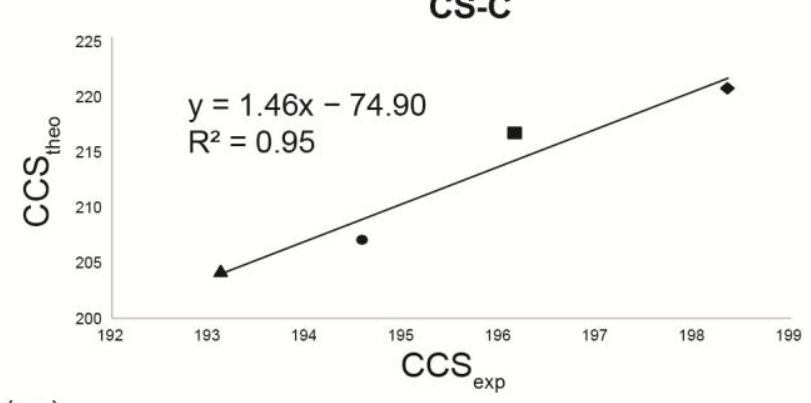

Figure 4. (a) Extracted IM-MS spectra of synthetic disaccharides CS-A (on the left) and CS-C (on the right) from deprotonated and alkali adduct species. (b) theoretical CCS values obtained from DFT optimized structures in function of experimental CCS values $\left([\mathrm{CS}-2 \mathrm{H}+\mathrm{Li}]^{-}\right.$are annotated by triangles, $[\mathrm{CS}-2 \mathrm{H}+\mathrm{Na}]^{-}$by circles, $[\mathrm{CS}-2 \mathrm{H}+\mathrm{K}]^{-}$by squares and $[\mathrm{CS}-2 \mathrm{H}+\mathrm{Cs}]^{-}$by lozenges.

By comparison, natural CS-C and CS-A disaccharides showed similar behaviors, i.e. an increase in $\mathrm{CCS}$ values in function of the cation size except for [CS-A-2H+Li] $]^{-}$and $[\mathrm{CS}-\mathrm{A}-2 \mathrm{H}+\mathrm{Na}]^{-}$ which were more folded than $[\mathrm{CS}-\mathrm{A}-\mathrm{H}]^{-}$(Figure S8, Supporting information). Furthermore, CS$\mathrm{C}$ analogues systematically showed less folded gas-phase conformation than CS-A species. Concerning CS tetra- and hexa-saccharides, ion mobility spectra were more complex, likely due to a mixture of several structures induced by different coordination sites of the metal ion (Figure S9, Supporting Information).

\section{Influence of the polymerization degree}

In addition to the nature of the metal cation on CS conformations, the influence of the polymerization degree on CS structures was also examined by IMS-MS. To this end, we carried out IMS-MS analysis of CS oligomers from di- to hexa-saccharides in order to determine the evolution of the shape of CS oligomers in the gas phase. CCS values are used instead of drift time as different ion mobility conditions were chosen according to the different sizes of the oligomers studied. Indeed, while drift times are dependent on the experimental conditions, CCS values are characteristic of an ion for a given charge state. Data presented in Figure 5 were 
deduced from three different ion mobility conditions and calibrated using dextran oligomers as reference in $\mathrm{N}_{2}{ }^{\left[{ }^{43]}\right.}$ Error due to charge state has to be considered, ${ }^{[56]}$ as the negative doubly charged of the calibrating agents (dextran oligomers) did not allow embracing the whole range of $\mathrm{m} / \mathrm{z}$ values for CS. Due to the important charge density of CS molecules, doubly- and triplycharged CS were calibrated from singly-charged dextran oligomers. Note that we do not aim at an exact determination of CCS values in this work, but only at delineating the CCS evolution according to the polymerization degrees.

The global evolution for both CS-C and CS-A isomers corresponds to a linear increase of CCS values in function of the oligomer sizes for a given charge state (Figure 5a). The study carried out for different charge states evidenced unfolding of the structures when the charge density increased.
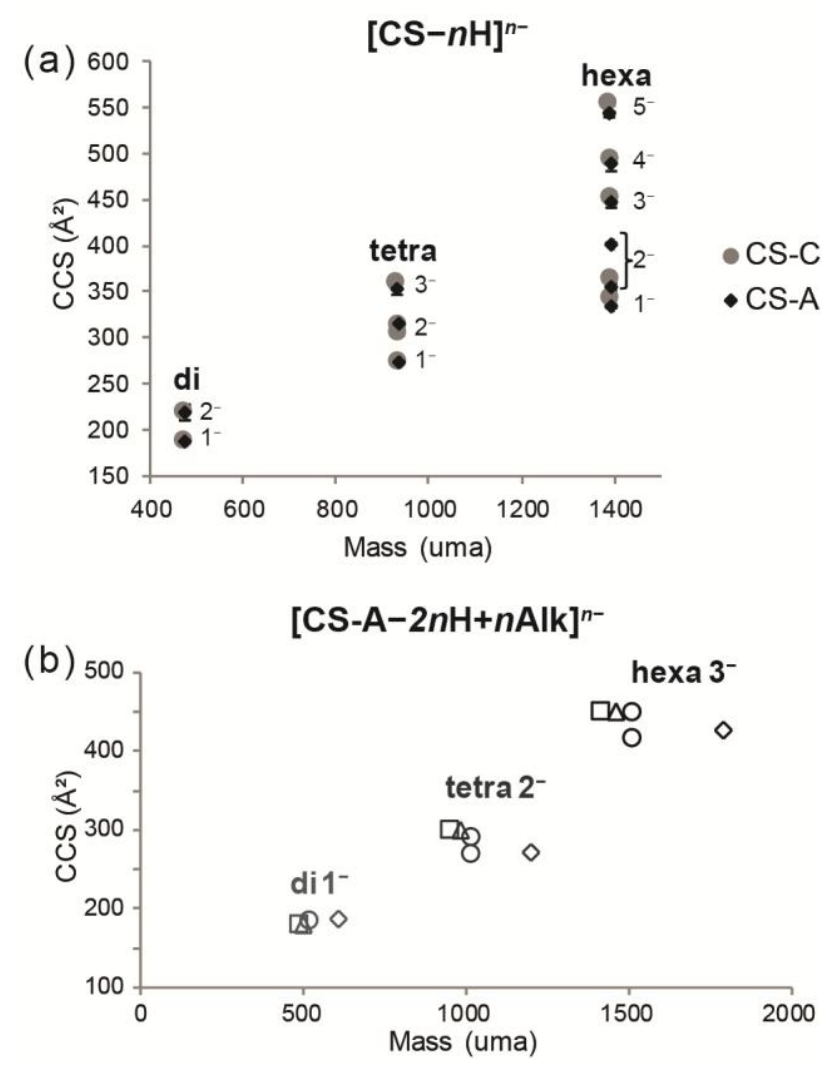

Figure 5. (a) collision cross section values in function of the mass of deprotonated di- tetra and hexa-saccharides of CS-C and CS-A isomers at different charge states. (b) collision cross section values in function of the mass of $[\mathrm{di}-\mathrm{CS}-\mathrm{A}-2 \mathrm{H}+\mathrm{Alk}]^{-}$, [tetra-CS-A-4H+2Alk] ${ }^{2-}$ and [hexa-CS$\mathrm{A}-6 \mathrm{H}+3 \mathrm{Alk}]^{3-}(\mathrm{Alk}=\mathrm{Li}$ annotated by squares, Alk $=\mathrm{Na}$ triangles, $\mathrm{Alk}=\mathrm{K}$ circles and $\mathrm{Alk}=\mathrm{Cs}$ lozenges).

From the Figure 5, it can be observed that the deprotonated oligomer ions $[\mathrm{CS}-\mathrm{nH}]^{\mathrm{n}-}$ showed mainly a single conformation except for $[\text { tetra-CS-C}-2 \mathrm{H}]^{2-}$ and $[\text { hexa-CS-A-2H }]^{2-}$. The presence of single conformation indicated either similar deprotonation sites or different 
deprotonation sites that did not influence gas-phase conformation of CS analogues. By contrast, the detection of two IMS signals for $[\text { tetra-CS-C}-2 \mathrm{H}]^{2-}$ and $[\text { hexa-CS-A-2H }]^{2-}$ indicated a competition between deprotonation sites resulting in different conformations. In the case of $[\text { hexa-CS-A-2H] }]^{2-}$, the important CCS difference observed between the two conformations could be assigned to sulfate deprotonation either on the two first or two last disaccharide units or

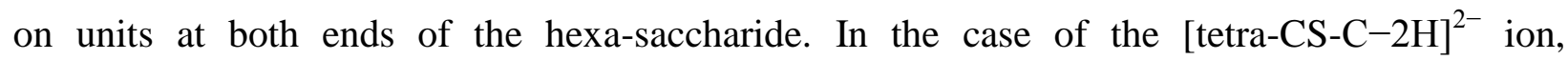
competition between carboxylic acid and sulfate group deprotonation was considered. This competition can also be observed at a lower extent for [di-CS-C-H] ${ }^{-}$(Figure 4a) as the IMS peak shape indicated two close conformations. The same experimental conditions were used for CS-C and CS-A analogues meaning that either deprotonation site competition did not occur for CS-A analogues, or that deprotonation of the sulfate/carboxylic acid groups resulted in the same conformation.

For alkali adducts $[\mathrm{CS}-\mathrm{nH}+\mathrm{Alk}]^{(\mathrm{n}-1)-}$, a linear increase of CCS with polymerization degree was also observed for CS-A when comparing [CS-A-2H+Alk $]^{-},[\mathrm{CS}-\mathrm{A}-4 \mathrm{H}+2 \mathrm{Alk}]^{2-}$ and $[\mathrm{CS}-$ $\mathrm{A}-6 \mathrm{H}+3 \mathrm{Alk}]^{3-}$. Assuming the chelation of one alkali metal per CS disaccharide units, the linearity observed means that similar chelation occurs per CS unit. By contrast, we observed multiple conformations of CS-C oligomers with the different alkali adducts, which did not allow the determination of a clear picture of the CCS evolution (Figure S10, supporting information).

\section{CONCLUSION}

A new approach discriminating $4 \mathrm{~S}$ and $6 \mathrm{~S}$ sulfation, which is useful to distinguish chondroitin sulfate isomers was proposed, based on the formation of alkali metal adducts and their analysis by tandem mass spectrometry in negative ionization mode. Most of the previously reported MS studies of chondroitin sulfate oligosaccharides were carried out on protonated form with some $\mathrm{H} / \mathrm{Na}$ exchange, mainly yielding $\mathrm{Y}$ and $\mathrm{Z}$ fragments due to glycosidic bond cleavage. These fragments are diagnostic for the mono-sulfation of the GalNAc moieties but are not diagnostic for the sulfate location. Here, we showed that cationization by alkali metal produced diagnostic ions specific of $4 \mathrm{~S}$ and $6 \mathrm{~S}$ sulfation, at $\mathrm{m} / \mathrm{z} 154$ and $\mathrm{m} / z, 139$ respectively, and resulting from cross-ring cleavage upon a simple MS/MS fragmentation.

While previous MS studies were performed on enzymatically produced CS oligosaccharides, mainly focused on disaccharides due to difficulties to get isomerically pure natural CS oligosaccharides of higher polymerization degree, this study was performed on synthetic CS oligosaccharides from dp2 to dp6. This method was able to unambiguously differentiate the synthetic CS-A and CS-S analogues from di- to hexa-saccharides. The comparative analysis of 
natural di-CS-A and di-CS-C showed that these diagnostic ions were also effective for CS oligosaccharides from natural source.

DFT calculations were performed on CS disaccharides to get some insights about the coordination scheme of the different alkali metals, and to yield a molecular base for the formation of the diagnostic ions. It was observed that the chelation of most alkali cations involves the sulfate group, the carboxylate group and the intra-cyclic oxygen of the glucuronic acid for CS-A, and the $\mathrm{C}_{4}$ hydroxyl group for CS-C.

Finally, experiments performed by ion mobility-mass spectrometry showed generally a linear evolution of collision cross sections in function of the polymerization degree for both CS-C and CS-A isomers. Moreover, linear evolution was observed between CS-A oligomers when one alkali adduct is present per CS disaccharide unit meaning that chelation mainly involves the sulfate group and the carboxylate group of the same CS unit. Given the similar gas-phase behavior of natural and synthetic disaccharides observed in MS/MS and IMS-MS experiments, we may reasonably assume that the gas-phase characteristics observed on synthetic CS analogues of higher polymerization degree could be likely extrapolated to natural CS species.

\section{ACKNOWLEDGEMENTS}

We would like to thank the LabEx CHARMMMAT (ANR-11-LABX-0039) for the attribution of a post-doctoral fellowship (SP) and the partial funding for the acquisition of the Bruker AMAZON SPEED ETD ion trap. This work was supported by the Region Ile-de-France for the acquisition of the ion mobility-mass spectrometer Synapt G2-Si HDMS. A generous allocation of computing time at the Centro de Computación Científica of the Universidad Autónoma de Madrid is also acknowledged.

\section{REFERENCES}

[1] F. N. Lamari, N. K. Karamanos, in Adv Pharmacol, Vol. 53, Academic Press, 2006, pp. 33.

[2] F. Horkay, P. J. Basser, A.-M. Hecht, E. Geissler, Macromolecules 2012, 45, 2882.

[3] K. Sugahara, T. Mikami, T. Uyama, S. Mizuguchi, K. Nomura, H. Kitagawa, Curr. Opin. Struct. Biol. 2003, 13, 612.

[4] S. Mizuguchi, T. Uyama, H. Kitagawa, K. H. Nomura, K. Dejima, K. Gengyo-Ando, S. Mitani, K. Sugahara, K. Nomura, Nature 2003, 423, 443.

[5] K. Sugahara, T. Mikami, Curr. Opin. Struct. Biol. 2007, 17, 536.

[6] O. A. Hamad, P. H. Nilsson, M. Lasaosa, D. Ricklin, J. D. Lambris, B. Nilsson, K. N. Ekdahl, PLoS One 2010, 5, e12889.

[7] P. A. Lemaire, L. Huang, Y. Zhuo, J. Lu, C. Bahnck, S. J. Stachel, S. S. Carroll, L. T. Duong, J. Biol. Chem. 2014, 289, 21562.

[8] M. A. Thelin, B. Bartolini, J. Axelsson, R. Gustafsson, E. Tykesson, E. Pera, A. Oldberg, M. Maccarana, A. Malmstrom, FEBS J. 2013, 280, 2431. 
[9] M. Bishnoi, A. Jain, P. Hurkat, S. K. Jain, Glycoconjugate J 2016, 33, 693.

[10] C. Ricciardelli, K. Mayne, P. J. Sykes, W. A. Raymond, K. McCaul, V. R. Marshall, W. D. Tilley, J. M. Skinner, D. J. Horsfall, Clin Cancer Res 1997, 3, 983.

[11] M. Ishii, N. Maeda, Glycobiology 2008, 18, 602.

[12] G. M. Miller, L. C. Hsieh-Wilson, Exp. Neurol. 2015, 274, 115.

[13] M. Rawat, C. I. Gama, J. B. Matson, L. C. Hsieh-Wilson, J. Am. Chem. Soc. 2008, 130, 2959.

[14] C. D. Nandini, K. Sugahara, Adv. Pharmacol. 2006, 53, 253.

[15] S. Mizumoto, D. Fongmoon, K. Sugahara, Glycoconjugate J 2013, 30, 619.

[16] C. Bernard, A. Prochiantz, Neural Plast. 2016, 2016, 7.

[17] G. O. Staples, J. Zaia, Curr. Proteomics 2011, 8, 325.

[18] J. Zaia, Mol. Cell. Proteomics 2013, 12, 885.

[19] F. Galeotti, N. Volpi, Anal. Chem. 2011, 83, 6770.

[20] B. Yang, Y. Chang, A. M. Weyers, E. Sterner, R. J. Linhardt, J. Chromatogr. A 2012, 1225, 91.

[21] G. Li, L. Li, F. Tian, L. Zhang, C. Xue, R. J. Linhardt, ACS Chem. Biol. 2015, 10, 1303.

[22] W. Wei, M. R. Ninonuevo, A. Sharma, L. M. Danan-Leon, J. A. Leary, Anal. Chem. 2011, 83, 3703.

[23] V. L. Gill, Q. Wang, X. Shi, J. Zaia, Anal. Chem. 2012, 84, 7539.

[24] O. M. Saad, J. A. Leary, J. Am. Soc. Mass Spectrom. 2004, 15, 1274.

[25] E. Sisu, C. Flangea, A. Serb, A. D. Zamfir, Amino Acids 2011, 41, 235.

[26] A. C. Robu, L. Popescu, C. V. Munteanu, D. G. Seidler, A. D. Zamfir, Anal. Biochem. 2015, 485, 122.

[27] K. Solakyildirim, Z. Zhang, R. J. Linhardt, Anal. Biochem. 2010, 397, 24.

[28] N. Volpi, Anal. Biochem. 2010, 397, 12.

[29] M. Kailemia, A. Patel, D. Johnson, L. Li, R. Linhardt, I. Amster, Eur. J. Mass Spectrom., 21.

[30] R. Huang, V. H. Pomin, J. S. Sharp, J. Am. Soc. Mass Spectrom. 2011, 22, 1577.

[31] J. Zaia, J. E. McClellan, C. E. Costello, Anal. Chem. 2001, 73, 6030.

[32] H. Desaire, J. A. Leary, J. Am. Soc. Mass Spectrom. 2000, 11, 916.

[33] C. Flangea, A. Serb, C. Schiopu, S. Tudor, E. Sisu, D. Seidler, A. Zamfir, in Open Chemistry, Vol. 7, 2009, p. 752.

[34] L. Jin, P. E. Barran, J. A. Deakin, M. Lyon, D. Uhrin, Phys. Chem. Chem. Phys. 2005, 7, 3464.

[35] M. Hermannova, A. M. Iordache, K. Slovakova, V. Havlicek, H. Pelantova, K. Lemr, J. Mass Spectrom. 2015, 50, 854.

[36] M. R. Schenauer, J. K. Meissen, Y. Seo, J. B. Ames, J. A. Leary, Anal. Chem. 2009, 81, 10179.

[37] Y. Seo, M. R. Schenauer, J. A. Leary, Int. J. Mass Spectrom. 2011, 303, 191.

[38] Y. Seo, A. Andaya, J. A. Leary, Anal. Chem. 2012, 84, 2416.

[39] M. J. Kailemia, M. Park, D. A. Kaplan, A. Venot, G. J. Boons, L. Li, R. J. Linhardt, I. J. Amster, J. Am. Soc. Mass Spectrom. 2014, 25, 258.

[40] J.-C. Jacquinet, C. Lopin-Bon, A. Vibert, Chem Eur J 2009, 15, 9579.

[41] S. Yamada, K. Sugahara, Curr Drug Discov Technol 2008, 5, 289.

[42] D. P. Smith, T. W. Knapman, I. Campuzano, R. W. Malham, J. T. Berryman, S. E. Radford, A. E. Ashcroft, Eur. J. Mass Spectrom. 2009, 15, 113.

[43] J. Hofmann, W. B. Struwe, C. A. Scarff, J. H. Scrivens, D. J. Harvey, K. Pagel, Anal. Chem. 2014, 86, 10789.

[44] A. D. Becke, J Chem Phys 1993, 98, 5648.

[45] C. Lee, W. Yang, R. Parr, Phys Rev B 1988, 37, 785.

[46] M. J. Frisch, e. al., Gaussian09, Revision C.01. See Supporting Information for complete citation. ed.

[47] P. J. Hay, W. R. Wadt, J Chem Phys 1985, 82, 270.

[48] W. R. Wadt, P. J. Hay, J Chem Phys 1985, 82, 284.

[49] P. J. Hay, W. R. Wadt, J Chem Phys 1985, 82, 299.

[50] E. D. Glendening, D. Feller, M. A. Thompson, J Am Chem Soc 1994, 116, 10657.

[51] I. Campuzano, M. F. Bush, C. V. Robinson, C. Beaumont, K. Richardson, H. Kim, H. I. Kim, Anal. Chem. 2012, 84, 1026.

[52] A. K. Rappe, C. J. Casewit, K. S. Colwell, W. A. Goddard, W. M. Skiff, J. Am. Chem. Soc. 1992, $114,10024$. 
[53] P. M. Lalli, Y. E. Corilo, M. Fasciotti, M. F. Riccio, G. F. de Sa, R. J. Daroda, G. H. Souza, M. McCullagh, M. D. Bartberger, M. N. Eberlin, I. D. Campuzano, J. Mass Spectrom. 2013, 48, 989.

[54] D. Ortiz, Q. Enjalbert, L. MacAleese, P. Dugourd, J.-Y. Salpin, Rapid Commun. Mass Spectrom. 2015, 29, 1135.

[55] B. Domon, C. Costello, Glycoconjugate J 1988, 5, 397.

[56] A. S. Gelb, R. E. Jarratt, Y. Huang, E. D. Dodds, Anal. Chem. 2014, 86, 11396. 